\title{
Lo bueno, si breve, tres veces bueno: la escritura aforística de Antonio Machado, Antonio Porchia y José Bergamín*
}

\author{
Lo bueno, si breve, tres veces bueno: \\ the Aphoristic Writing of Antonio Machado, \\ Antonio Porchia and José Bergamín
}

\author{
Paulo A. Gatica Cote \\ Universidade de Santiago de Compostela \\ paulo.gaticacote@gmail.com \\ ORCID iD: https://orcid.org/0000-0003-1534-3404
}

\section{RESUMEN}

Este artículo reflexiona sobre la escritura aforística a partir de una tríada de autores de gran relevancia para la evolución del género en los siglos XX y XXI: Antonio Machado, Antonio Porchia y José Bergamín. La obra de estos creadores supone un buen punto de partida para analizar algunas de las principales características del aforismo hispánico contemporáneo.

Palabras Clave: aforismo; Antonio Machado; Antonio Porchia; José Bergamín.

\section{ABSTRACT}

This paper aims to reflect on aphoristic writing from a triad of authors of great relevance to the evolution of the aphorism in the $\mathrm{XX}^{\text {th }}$ and $\mathrm{XXI}^{\text {st }}$ centuries: Antonio Machado, Antonio Porchia and José Bergamín. The work of these authors is a good starting point to analyze some of the main characteristics of the contemporary Hispanic aphorism.

Key words: Aphorism; Antonio Machado; Antonio Porchia; José Bergamín.

* Este trabajo forma parte de las actividades del proyecto de investigación «PERFORMA2. Metamorfosis del espectador en el teatro español actual» (PID2019-104402RB-I00) (2020-2023), financiado con una ayuda del Ministerio de Ciencia e Innovación en el marco del Plan Estatal de Investigación Científica y Técnica y de Innovación 2017-2020, y dirigido por el profesor Anxo Abuín González. 
Y la luz de sus pensamientos casi siempre se veía arder.

Rubén Darío

Generalmente, la crítica distingue entre un aforismo de corte 'clásico', hermano de otras fórmulas sapienciales como la máxima o el proverbio, y un aforismo 'moderno', ligado a la consolidación de la subjetividad romántica. Sin embargo, habría que matizar con Marco Ángel que el nacimiento de un nuevo tipo de aforismo no implica la desaparición de los modelos anteriores (2011, 86). Especialistas como Werner Helmich o José Ramón González abogan por una diferenciación cualitativa: un deslinde entre aforismos conceptuales o filosóficos, emparentados con la máxima clásica, y aforismos metafóricos, analógicos o poéticos, de formulación moderna y de raíz lírica (Helmich 2006, 44; González 2013, 41). Como se verá en el presente artículo, el género aforístico, signado por la formulación breve y por la 'veracidad' de sus enunciados, ha ido incorporando otras modulaciones a lo largo de su evolución; de ahí que el criterio histórico deba ser confrontado con la realidad de una forma que admite una amplia gama de lecturas e interpretaciones.

Lógicamente, cualquier nómina siempre resulta insuficiente, pues, además de nacer con el estigma de la parcialidad, esta se suele presentar con el tranquilizador sobrenombre de 'muestra significativa o representativa' que recogería un falaz promedio aforístico. Por esta razón, si bien todo estudio profundo sobre la brevedad no debería soslayar ni las «ideas líricas» de Juan Ramón Jiménez ni la inclasificable escritura de Ramón Gómez de la Serna, las figuras de Antonio Machado, Antonio Porchia y José Bergamín ofrecen algunos de los mejores testimonios acerca de la variabilidad e hibridez del aforismo contemporáneo.

\section{Antonio Machado}

La ascendencia poética y vital de Antonio Machado (1875-1939) es innegable en la literatura española y, de manera singular, en la segunda generación de posguerra o en los poetas de la experiencia. Aparte de sus celebradas composiciones en libros inolvidables como Soledades, galerías y otros poemas o Campos de Castilla, se puede 'rescatar' una faceta menos conocida -menos elogiada, hasta se podría decir ${ }^{1}-$ del escritor sevillano, aunque constantemente citada en boca de sus heterónimos Abel Martín y Juan de Mairena: la vertiente sapiencial o sentenciosa. No obstante, esta tendencia gnómica casa a la

${ }^{1}$ Llaman poderosamente la atención algunas referencias adversas sobre sus proverbios. Por ejemplo, para Dámaso Alonso estas composiciones suponen «poemas minúsculos, definidores, dogmáticos, condensación de turbias intuiciones puramente cerebrales» (1961, 149-150). 
perfección con sus inquietudes literarias e intelectuales: junto a «Retrato», «La tierra de Alvargonzález», «Por tierras de España», «A un olmo seco» u «Orillas del Duero», descuella una sección de especial relevancia para el aforismo hispánico: los «Proverbios y cantares» ${ }^{2}$.

En este sentido, Gonzalo Sobejano advierte en un lúcido artículo titulado «La verdad en la poesía de Antonio Machado» que el paso de la rima al proverbio viene motivado por la propia búsqueda de la verdad a través de tres vías de experimentación formal: rimas, cuadros y proverbios. Según el crítico, las

«rimas» son casi todas las poesías de su primer libro, pero algunas tienden a la concisión de la sentencia y otras a un mayor desenvolvimiento; en el segundo libro predomina la composición extensa de carácter descriptivo, «cuadro» podría llamarse, pero hay algunas rimas breves y aparecen ya proverbios y cantares; en el tercer libro éstos son, por su abundancia y calidad, lo más destacado, pero no faltan rimas, sobre todo extensas. Advertido lo cual, puede con todo mantenerse, para mayor claridad, esta distinción básica: Soledades es el libro de las «rimas», Campos de Castilla el libro de los «cuadros», Nuevas canciones el libro de los «proverbios» (1976, n.p.).

Geoffrey Ribbans señala en su fundamental introducción a la obra que esta querencia hacia el cantar viene heredada de la ingente recopilación de cantes flamencos realizada por su padre Antonio Machado Álvarez (Machado 1989c, 79) -el folclorista Demófilo-, quien se propuso ofrecer en Cantes Flamencos y Cantares «una gallarda muestra de las condiciones artísticas del gran poeta anónimo» (Machado Álvarez 2004, 5). Además, el acervo lingüístico popular, repleto de frases hechas, locuciones y hallazgos léxicos, supone una fuente casi inagotable de aforismos por su sobrecarga de sentido acumulado a través del uso. Por ejemplo, Juan de Mairena, como experto en Retórica, aconseja buscar en este rico patrimonio la manera de romper, resignificar o subvertir las engastadas cadenas léxicas de la lengua española ${ }^{3}$. Como él mismo explica:

${ }^{2}$ En concreto, los primeros testimonios de la serie de 53 «proverbios y cantares» aparecieron en 1909 durante su etapa soriana y fueron integradas en la primera edición de Campos de Castilla (1912). Por tanto, coincide en el tiempo con su estancia en París, becada por la Junta de Ampliación de Estudios, donde asiste a los cursos de filosofía que imparte Henri Bergson en el Collège de France (1911). Además, se podrían incluir las ocho «parábolas» dentro de la línea sentenciosa. En su edición crítica de Campos de Castilla, Ribbans indica que los textos se publican en 1916 con el título de «Apuntes, parábolas, proverbios y cantares». Desde el primer poema se observa una filiación con las máximas moralistas francesas a través de la imagen de las «pompas de jabón»: «Nunca perseguí la gloria / ni dejar en la memoria / de los hombres mi canción; / yo amo los mundos sutiles, / ingrávidos y gentiles / como pompas de jabón. / Me gusta verlos pintarse / de sol y grana, volar / bajo el cielo azul, temblar / súbitamente y quebrarse» (1989a, 568-569).

${ }^{3}$ En la actualidad se podría mencionar la aforística de Carmen Camacho, quien ha encontrado en el «habla» popular y en las expresiones de la calle el germen de muchas de sus minimás: «Las minimás piden mirada y palabras punzantes. Y veneran el saber del 
Volvamos a nuestras frases hechas, sin cuya consideración y estudio no hay buena Retórica. Reparad en ésta: abrigo la esperanza y en la mucha miga que tiene eso de que sea la esperanza la que se abrigue. La verdad es que todos abrigamos alguna, temerosos de que se nos hiele (Machado 2010, 109).

De este modo, el «capital flotante» o «masa» de sabiduría popular de carácter «empírico, verdaderamente real y no abstracto, de sus escasos conocimientos» del que hablara Demófilo $(2004,6,12)$ va a ser reelaborado por Machado sin variar el esquema retórico de los cantares: breves composiciones asonantadas con rimas alternas o en los versos pares que, con algunas excepciones, oscilan entre los cuatro y diez versos. Si se sigue la descripción clásica de Rafael Gutiérrez, los «proverbios y cantares» son

de reducido tamaño y variada métrica [...], definitorios y sentenciosamente didácticos; su ordenación no parece obedecer a un hilo consecuente, aunque visto más de cerca, se muestran como variaciones, aproximaciones, repeticiones $\mathrm{y}$, a grandes rasgos, como uno más entre los múltiples resúmenes de la poesía de Machado $(1969,46)$.

Por añadidura, comenta Ribbans que este proceso de miniaturización cognoscitiva emprendido en Campos de Castilla irá exhibiendo con el paso del tiempo un mayor interés «por lo metafísico, lo elíptico y lo abstracto» (1989c, 83). Según el hispanista inglés, uno de los mejores ejemplos de este tránsito se observa en el poema xxxv «Hay dos modos de conciencia», uno de los más extensos de la serie, en el que Machado opone un tipo de conocimiento intuitivo o razón poética, que «ilumina modestamente lo ignoto», al modo científico-analítico, «incapaz de captar la esencia huidiza del tiempo» (1989c, 83):

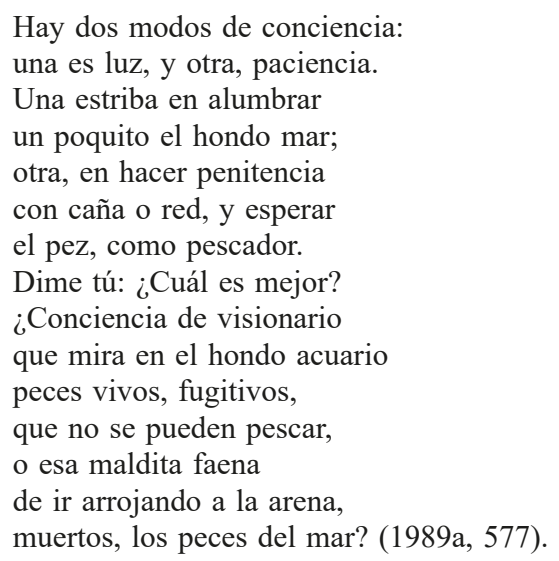

pueblo» $(2016,91)$. Sirva de ejemplo el siguiente aforismo: «Freír la cebolla hasta que pierda el orgullo» (Mi abuela, dictándome una receta de cocina) $(2009,29)$. 
Ahora bien, aunque el aforismo constituye con frecuencia una unidad autosuficiente, se presenta en una macroestructura, donde se inserta en forma de «momentos de un meditar coherente sobre ciertas verdades (morales y de conocimiento)» (Sobejano 1976, n.p.). Así, esta suerte de reflexión mediante iluminaciones adquiere un carácter dialógico en el que el yo, por un lado, se abre e interpela a la otredad - « ¿Tu verdad? No, la Verdad, / y ven conmigo a buscarla. / La tuya, guárdatela» (Machado 1989a, 643)- y, por otro, puede aparecer subsumido por el «tú esencial»: «No es el yo fundamental / eso que busca el poeta, / sino el tú esencial» (Machado 1989a, 633). En los textos paralelísticos XXXVII, XXXVIII, XLII y XLIII el sevillano interroga a un tú ausente por medio de un juego de preguntas y respuestas que bebe de la sabiduría popular:
¿Dices que nada se crea?
No te importe, con el barro de la tierra, haz una copa para que beba tu hermano. $* * *$
¿Dices que nada se pierde?
Si esta copa de cristal se me rompe, nunca en ella beberé, nunca jamás.

\author{
¿Dices que nada se crea? \\ alfarero, a tus cacharros. \\ Haz tu copa y no te importe \\ si no puedes hacer barro (1989a, 577-578). \\ $* * *$ \\ Dices que nada se pierde, \\ $\mathrm{y}$ acaso dices verdad; \\ pero todo lo perdemos \\ y todo nos perderá (1989a, 579).
}

Sin embargo, será en Nuevas canciones (1917-1930), libro-bisagra en la trayectoria del poeta sevillano, en el que se exponga la madurez de su escritura lapidaria en una nueva serie de noventa y nueve «proverbios y cantares». Manuel Alvar explica que, a diferencia de la primera, en esta serie «la continuidad no lo es en cuanto al espíritu, sino en cuanto a la forma. Los cantares no son lo mismo que las canciones» (Machado 1984, 45). La «reedición», dedicada a José Ortega y Gasset ${ }^{4}$, muestra un mayor aquilatamiento expresivo de la «carga» gnómica en forma de soleares, cuartetas y, en menor medida, dísticos. En esta línea, destaca la primera composición, una soleá que sirve de pórtico de la sección y que remeda el axioma inmanentista de George Berkeley Esse est percipi o «Ser es ser percibido» a modo de clave interpretativa del conjunto:

\author{
El ojo que ves no es \\ ojo porque tú lo veas: \\ es ojo porque te ve (Machado 1989a, 626) .
}

\footnotetext{
${ }^{4}$ La dedicatoria al filósofo español no es baladí, puesto que Ortega y Gasset, además de suponer un intertexto explícito, era el director de la Revista de Occidente, publicación en la que Machado adelanta algunos textos en el tercer número de 1923.

${ }_{5}$ Ejemplo de la mencionada variación que caracterizaría a los proverbios y cantares se encuentra, entre otros, en el poema XL: «Los ojos por (los) que suspiras, / sábelo bien, / los
} 
Para el sevillano, la soleá, uno de los palos del cante jondo, constituye un «escueto y rápido vehículo del pensamiento» (Sobejano 1976, n.p.) que puede albergar bajo su apariencia «popular» contenidos alejados de su origen flamenco. Según Sobejano, la soleá machadiana se sitúa en la intersección entre la reflexión metafísica, cognoscitiva, ética y estética para comunicar cuatro «ideas vividas al tú esencial» sobre la otredad, la continuidad, la autenticidad y la contemplación (1976, n.p.). En cierto modo, los proverbios y cantares suponen la actualización del aforismo poético-filosófico que practicaran los escritores del Círculo de Jena o Friedrich Nietzsche. Como expresa Friedrich Leopold von Hardenberg, más conocido como Novalis, en uno de sus «gérmenes»: «La separación entre el poeta y el pensador es sólo aparente y desventajosa para ambos. Es indicio de enfermedad y de constitución enfermiza» $(2006,39)$.

En efecto, existe una poderosa unidad de vida y pensamiento en la obra del escritor sevillano. Particularmente, dicha integración se refleja en el viaje de ida y vuelta entre la filosofía y la poesía protagonizado por sus dos portavoces que, en calidad de «persona interpuesta», verbalizan, según Neila (2010, 1617), el desplazamiento de la «poética a la filosofía»-Abel Martín- y de la «filosofía a la poética»-Juan de Mairena- ${ }^{6}$. Es más, la asociación pascaliana corazón-razón no solo es retomada por Antonio Machado, sino que se transforma en el híbrido co(n)razón-compasión que ha de mostrar en todo momento la inteligencia lírica. De esta manera, mientras que el primer movimiento despliega un pensar poético destemporalizado, «esencialmente heterogeneizador» de cualquier centralismo lógico-matemático, el segundo, en cambio, se fundamenta en su gran hallazgo poético -la poesía es palabra esencial en el tiempo- para articular una metafísica profundamente humana: «el diálogo del hombre, de un hombre con su tiempo» (Neila 2010, 17).

Igualmente, De un cancionero apócrifo (1928) y, sobre todo, el segundo Juan de Mairena -Juan de Mairena (sentencias, donaires, apuntes y recuerdos de un profesor apócrifo) (1934-1936)- representan un estadio final en la literatura sapiencial de Antonio Machado: el desembarco de una filosofía asistemática consecuente con «un mundo esencialmente apócrifo», que huye de cualquier identificación con el sujeto poético, así como la paradójica consolidación de un yo filosófico incomprendido, incomprensible e «inconfesable» (Cejudo 1986, 109) ${ }^{7}$. En palabras de Eustaquio Barjau: «la imposibilidad de encontrar la verdad de uno mismo en una personalidad única y coherente, y la consiguiente necesidad de multiplicarse en apócrifos es lo que hace que Antonio

ojos en que te miras / son ojos porque te ven» (1989a, 634).

${ }^{6}$ En palabras del escritor sevillano: «Hay hombres, decía mi maestro, que van de la poética a la filosofía; otros que van de la filosofía a la poética. Lo inevitable es ir de lo uno a lo otro, en esto, como en todo» (1989b, 1998).

7 Para Pablo Cejudo, la idea de apócrifo sería aplicada por Antonio Machado en su sentido etimológico: oculto, secreto, inconfesado $(1986,109)$. 
Machado conciba la obra literaria como una creación de segundo grado» (1974, 105).

Así pues, el «neosocratismo» machadiano (Barjau 1974, 112) en boca de Juan de Mairena, transmisor-comentador de las enseñanzas de su maestro Abel Martín, verbaliza una pedagogía del conocimiento que se cimienta en la duda que azuza cualquier reflexión. A este respecto, José Luis Abellán aclara que lo apócrifo cumple tanto «una función heurística y hermenéutica de comprensión de uno mismo» como otra «de carácter utópico, como medio de cambio y transformación de lo real» (1979, 82-83). El librepensador Mairena, «yo filosófico» machadiano «un poco poeta y un poco escéptico», se posiciona a medio camino entre el escepticismo radical y una mirada inquisidora que renuncia $-\mathrm{y}$, de paso, denuncia- a cualquier prejuicio. En este sentido, Machado es un contorsionista de la verdad, no tanto por negar su posible existencia, sino por considerar la entelequia que el propio concepto acarrea. Las verdades de Agamenón, las enuncie quien las enuncie, no convencen al porquero que ni pretende vencer ni tampoco se deja por la supuesta irrefutabilidad de la lógica (1989b, 1909). Por ello, en medio de un clima de degradación moral, resurge su figura apócrifa para confrontar los saberes, valores y virtudes falsa e hipócritamente elevados a dogma de fe con otros de «tamaño humano»:

Vosotros sabéis que yo no pretendo enseñarnos nada, y que sólo me aplico a sacudir la inercia de vuestras almas, a arar el barbecho empedernido de vuestro pensamiento, a sembrar inquietudes, como se ha dicho muy razonablemente, y yo diría, mejor, a sembrar preocupaciones y prejuicios; quiero decir juicios y ocupaciones previos y antepuestos a toda ocupación zapatera y a todo juicio de pan llevar (Machado 1989b, 2075).

En resumidas cuentas, el siempre peliagudo asunto de la «verdad» adquiere en el escritor sevillano una hondura que recupera la dualidad poesía-filosofía entendida como dos talantes que aspiran a la convergencia más que a su escisión lógico-metafísica. Si bien establece Machado que «los grandes poetas son metafísicos fracasados» y «los grandes filósofos son poetas que creen en la realidad de sus poemas», el escritor aprecia en dicha conjunción una enseñanza implícita: el valor poético y aporético de la razón (Machado 1989b, 1995) que, en buena medida, asume la escritura aforística.

\section{ANTONIO PORCHIA}

Ricardo Gullón advierte en la obra de Machado un «substratum filosófico» (2006, n.p.) que, sin alcanzar la categoría de sistema, se hace visible en cada una de sus composiciones. De igual manera, esta fuerte imbricación vida-literatura se va a reproducir en la trayectoria de Antonio Porchia (1885-1968). Aun así, el poeta argentino de ascendencia italiana ostenta en el panorama poético 
del siglo XX el estatus de rara avis. Sus Voces (1943) se han convertido en pequeñas joyas de difusión escasa -la primera edición sumaba apenas mil ejemplares en una oscura editorial independiente «Impulso»- y tardía -a los 58 años-. De hecho, el autor permaneció durante mucho tiempo en un régimen de semiolvido por el canon -su obra circuló de forma autógrafa entre unos pocos iniciados» (Rodríguez 1975) que la leyeron con devoción- hasta la intervención de Roger Caillois ${ }^{8}$. El francés, colaborador de la revista Sur dirigida por Victoria Ocampo, reconoce la hondura expresiva del poeta y se erige en su principal valedor en los medios literarios de la época, así como en el encargado de la primera traducción al francés de las Voces $^{9}$.

A pesar de su rápida inscripción en el territorio aforístico, Antonio Porchia niega cualquier parecido con el género: «Jamás digan que escribo aforismos. Me sentiría humillado» $(2006,30)$. El creador argentino reclama la autonomía de una forma de escribir genéricamente indefinida y que, por tanto, tiene en esa indefinición su esencia. De acuerdo con la poética porchiana, las Voces son el fruto de una experiencia esencializadora y directa con el mundo (Benarós 1988); sin embargo, la crítica especializada advierte, por un lado, una cierta visión «trágica» y desesperanzada en sus textos con un acercamiento a la filosofía taoísta (Saubidet 1979; Cruz Pérez 1994) o a la mística (Porchia 2006, 21); y, por otro, identifica las posibles fuentes clásicas de las Voces, entre las que se suelen citar los clásicos del pensamiento aforístico Heráclito, Pascal, La Rochefoucauld, Nietzsche, Lichtenberg o William Blake (Cruz Pérez 1994, 146-147; Porchia 2006, 21). En palabras de Cruz Pérez:

Porchia enriquece sobremanera la poesía metafísica argentina, que puede empezar con Macedonio Fernández y culminar con Roberto Juarroz [...]. Podríamos situar, asimismo, a esta poesía en una corriente densa y esencial de pensamiento, que nos viene de Heráclito, pasa por Nietzsche y se asienta en el pensamiento aforístico de Elías Canetti. Con Heráclito, Porchia comparte el sentido de la contradicción; con Nietzsche, el del abismamiento y cierta recurrencia de la imagen, y con Canetti, la visión de la realidad superabierta, flexible e inquietante $(1991,73)$.

${ }^{8}$ Las primeras voces salen a la luz con dicha denominación en La Fragua (1943), una publicación de izquierdas en la que colaboró entre 1938 y 1939, aunque habrá que esperar hasta 1948 para que aparezca la segunda edición en el sello Impulso (Porchia 2006, 17-19).

${ }^{9}$ La crítica suele considerar la llegada de la voz de Porchia a los lectores franceses como el catalizador del futuro reconocimiento de buena parte de la intelectualidad europea y americana. Henry Miller, Raymond Queneau o André Breton frecuentaron y alabaron las composiciones del creador argentino hasta el punto de conseguirle en 1949 el premio internacional a autores extranjeros otorgado por el Club Francés del Libro. En las últimas décadas, el testigo lo han recogido las firmas Hachette en el país galo y Pre-Textos en España, editorial que publicó en 2006 las voces completas en una excelente edición y acompañadas de un serio estudio crítico. 
Aunque en la ejemplar introducción de Daniel González Dueñas y Alejandro Toledo se subraya el panteísmo porchiano que postula la «unicidad de todo, y de todo en él» $(2006,17)$, el despojamiento extremo adquiere en Porchia rasgos desubjetivadores y desobjetivadores que han llevado a establecer un paralelismo entre sus voces y la oralidad. Para críticos como Fabio Morábito, el argentino no escribe en un sentido literario o escritural al uso, sino que, al «hablar» sus reflexiones, «la voz se adelgaza hasta volverse impersonal y la oralidad, sin dejar de ser tal, no se asimila por completo al habla» $(2008,151)^{10}$; de ahí que prefiera definirlas como un «nítido precipitado de escritura» (Morábito 2008, 151) en vez de recurrir a la panoplia de géneros literarios. Curiosamente, esta aproximación desde el plano de la lengua fue apuntada con anterioridad por Pablo Gasparini, quien incide en la condición de «extranjero lingüístico» que afectaba a Porchia; es decir, en las peculiaridades de su lengua materna -el italiano- y su aprendizaje en la escuela. Según el crítico, en esta etapa se vislumbraría «tanto la emergencia de cierta discursividad anarquista como la presencia de una atávica religiosidad cristiana» $(2009,74)$ que van a justificar, en cierto modo, la peculiar transparencia y humanidad de las voces.

Sin lugar a dudas, existe una particular correspondencia entre las composiciones de Porchia y una línea trascendentalista que bordea la epifanía o la revelación cotidiana. En opinión de Caillois, la «adivinatoria» porchiana rechaza el intelectualismo entendido como esfuerzo o tensión (Porchia 2006, 21); así, su escritura se vuelve «sensible» y notablemente empática, pero sin que pueda confundirse esta manifiesta y clarividente per/receptividad quintaesenciada con ignorancia o dejadez. Por esta razón, Daniel González y Alejandro Toledo señalan que las voces «más que un género en sí mismas, son un espíritu» (2006, 29) que repudia «toda normalización» estética o, incluso, gramatical (Gasparini 2009, 78): una poética que busca dar voz al pensamiento mediante un lenguaje finito y convencionalizado.

Además, como advierte Gasparini, dicho proceso «normalizador» redundaría negativamente en la apertura semántica del texto. La aparente agramaticalidad de muchas de las voces evita «la traducción del sentido poético al sentido dóxico» $(2009,78)$; de esta forma, el carácter poético no solo desarticula cualquier efecto de clausura semiótica sobre un enunciado ortotipográficamente cerrado, sino que también teje una red de relaciones y resonancias no previstas dentro y fuera de la página. Aquí, Laura Cerrato recurre a la imagen del poeta que balbucea en San Juan de la Cruz o de un heideggeriano regreso al pre-lógos para describir el trabajo de reflexión metalingüística de Porchia $(1992,13)$.

Pese a su negativa expresa a establecer cualquier semejanza con otras formulaciones breves y sapienciales, se percibe una innegable afinidad con un

10 Para Morábito, Antonio Porchia parece pintar sus reflexiones, puesto que el creador argentino «se sentía más próximo a la pintura que a la literatura» en el cultivo de sus voces $(2008,145)$. 
determinado modo de aprehensión poética basado en la intuición -el olfato para desvelar lo oculto- y en un cierto panteísmo espiritual -la vista para percibir/ recibir lo oculto sobrevenido-. No obstante, esta dicotomía de la sensibilidad no representa los extremos entre los cuales se moverían las voces, ya que, incluso en aquellas aparentemente contradictorias, Porchia socava el estatuto dialéctico del conocimiento para proponer, en la terminología de González y Toledo, un «tercero armonizante» $(2006,242)$. Desde este punto de vista, la razón porchiana supone «una nueva posibilidad estética y epistemológica» (Sampedro 2009, 221) radicalmente inclusiva, puesto que parte de la aceptación y del diálogo en vez fortalecerse en la lógica de pares opositivos. Para el argentino, A/no-A, Sí/No no son más que una discriminación de las múltiples posibilidades del entre y de la conjunción:

430. Las cosas que más contrastan entre sí son las que menos contrastan conmigo (Porchia 2006, 81). $* * *$

548. Y si no puede haber un extremo sin el otro extremo, ¿cómo pudo haber un infierno sin paraíso? (ibíd., 97).

569. Soy lo bajo y lo alto de mí. No lo bajo de mí. No lo alto de mí. Porque lo bajo y lo alto de mí no he podido separarlos (ibíd., 99).

736. Siempre estoy en los extremos de mí mismo y, en todos ellos, hallo mi término medio (ibíd., 118).

Evidentemente, esta suerte de convivencia -en ocasiones, connivencia- de los contrarios no supone una novedad en la aforística contemporánea. Aparte de la escritura transversal de Rafael Argullol, se localizan poéticas similares que delatan la inoperancia de unos extremos que fungen de barreras o aprioris del pensamiento ${ }^{11}$. De acuerdo con Helmich, la relativa unidad y coherencia de las voces es cuestionada por su ambigüedad y contradicciones $(1998,98)$. En este sentido, la fuerza del conjunto radica, por un lado, en la sistematización de la duda como garantía de su asistematicidad y, por otro, en una verbalización transparente de una lengua tan pensada como hablada. De todas formas, más allá de la prédica de un cierto «ilogicismo» imbuido por el wu wei o la noacción taoísta - «Desde hace mil años me pregunto: ¿qué haré ahora? Y aún no necesito responderme» (2006, 45); «La razón se pierde razonando» (2006, 48 )-, las voces representan una posible salida del solipsismo al que conduce la verdad lógica. Por ello, Porchia propone «vaciar» el ego, suerte de formaliza-

${ }^{11}$ Por ejemplo, la aforística de Ramón Andrés, agrupada bajo el revelador título de Los extremos, desarrolla precisamente esta cuestión: «El escéptico lo es porque ha tenido en cuenta los extremos» $(2011,30)$. 
ción gramatical del sujeto cognoscente, para impregnarse de todo cuanto le rodea en su transitar «absorto» o desapercibido:

2. Quien ha visto vaciarse todo, casi sabe de qué se llena todo (Porchia 2006, 39).

211. Puedo andar por todas las cosas, pero así, como ando ahora: no prendido de ninguna cosa (ibíd., 59).

Claro está, cualquier proceso de despojamiento o fusión del yo en un yo/ no-yo absoluto no alcanza la deseada disolución del sujeto, aunque sí puede constituir una entidad pseudopanteísta que supere la escisión y abismamiento psicologista de la subjetividad-racionalidad modernas. Precisamente, Cerrato estima que la condición oracular y extraterritorial de Porchia se va a traducir en el permanente creer/descreer, decir/desdecir y nombrar/desnombrar de unas voces «que enfrentan brutal e insólitamente dos lugares alejados» $(1992,14)$.

Con todo, la expresión aforística ejecuta tanto un movimiento de apertura como otro de cierre. En el caso de Porchia, la sabiduría de la sencillez promueve una forma de autoconocimiento que encuentra en la carencia y en lo pequeño una hondura y plenitud insondables:

6. Las pequeñeces son lo eterno, y lo demás, todo lo demás, lo breve, lo muy breve (Porchia 2006, 39).

***

241. La verdad, cuando es la verdad de lo pequeño, casi es toda verdad, y cuando es la verdad de lo grande, casi es toda duda (ibíd., 62).

246. Todo: lo grande de los pequeños. Nada: lo grande de los grandes (ibíd., 63). $* * *$

982. Me enseñaron a ganarlo todo y no a perderlo todo. Y menos mal que yo me enseñé, solo, a perderlo todo (ibíd., 145).

Aunque, según Helmich, predominan las formas de pensamiento que trabajan con relaciones lógicas como la antítesis o la paradoja y los juegos de palabras basados en maniobras de sustitución, repetición e, incluso, paronomasias (1998, 90-91), cada voz se sitúa en «un más allá de la racionalidad del lenguaje» (González y Toledo 2006, 258). En consecuencia, resulta complicado inscribir la obra del argentino dentro del dominio aforístico sin tropezar en algún momento con la dualidad poético-filosófica ya vista en Antonio Machado.

Sin embargo, a diferencia del poeta sevillano, en Porchia no sobresale el neosocratismo regenerador, sino una inoperante perplejidad y asombro ante la realidad visible e invisible consignada en las voces con una «franqueza» casi diarística. Si se acepta que, tal como afirma Henry Sampedro sobre el autor, «la única forma de ver en la esencia de las cosas viéndolas verdaderamente, consiste en ser uno con ellas» $(2009,224)$, la escritura porchiana ha de aspirar a una visión teóricamente totalizante. En cambio, las voces no plantean ningu- 
na reducción o integración de la multiplicidad; de ahí que la brevedad se abra tanto a las formulaciones aforísticas clásicas como a las denominadas analógicas, pero filtradas por un lenguaje gramatical y cognoscitivamente tensado.

En suma, se podría afirmar que el creador argentino retoma la senda aforística de los pensamientos caminados y de los errores rebosantes de aciertos y dobleces. De manera especial la verdad, desidealizada y puesta en perspectiva «humana», va a significarse gracias a su paradójica renuncia a discursivizar las voces, a convertirlas en minuciosos y atinados aforismos como el siguiente: «Lo hondo, visto con hondura, es superficie» (2006, 61). Para Cruz Pérez, «la radicalidad de Porchia está en abrir la realidad, haciendo de la consciencia la luz de la imaginación [...]. La palabra no es un vómito, sino una decisión de apertura» (1991, 72-73). Desde esta perspectiva, las voces, definidas vagamente por el autor como «algo» que le llega por medio del oído «cuando es el momento» (Porchia 2006, 174), aparecen libres del acostumbrado envoltorio «argumental»; por consiguiente, incluso en sus construcciones más lógicas, surgirá una inestabilidad o desequilibrio en el plano del significante y del significado:

393. Y si nada se repite igual, todas las cosas son últimas cosas (Porchia 2006, 77).

497. Ahora el instante, luego lo eterno. El instante y lo eterno. Y sólo el instante es tiempo, porque lo eterno no es tiempo. Lo eterno es recuerdo del instante (ibíd., 91).

500. Quien penetra en la dura roca pierde la dureza de la roca y halla la suya en la dura roca (ibíd., 92).

$* * *$

518. Lo que dicen las palabras no dura. Duran las palabras. Porque las palabras son siempre las mismas y lo que dicen no es nunca lo mismo (ibíd., 94).

\section{José Bergamín}

En las primeras décadas del siglo XX sobresalieron en el ámbito español las plumas de escritores de la talla de Juan Ramón Jiménez, Giménez Caballero, Gómez de la Serna, Eugenio D’Ors o Benjamín Jarnés, quienes compartieron con sus coetáneos Antonio Machado y Antonio Porchia la denominada «ambición de la brevedad» (Salinas 1970; Dennis 1986). En este contexto, la obra del madrileño José Bergamín (1895-1983), miembro destacado de la Generación del 27, supone una de las trayectorias literarias más completas y originales de la Edad de Plata.

En concreto, la producción aforística de Bergamín se concentra en cinco libros: El cohete y la estrella (1923), El arte de birlibirloque (1930), La cabe- 
za a pájaros (1934), Aforismos de la cabeza parlante (1983) y el recopilatorio Las ideas liebres $(1998)^{12}$. Aparte de la distancia temporal y vital -exilio incluido- entre sus primeras incursiones y las últimas, llama poderosamente la atención la hibridez formal y temática sugerida por los títulos elegidos, que abarcan tanto un tratado sobre el toreo como reflexiones estético-metafísicas atravesadas por una lúdica irreverencia. En este sentido, Nigel Dennis subraya el carácter proteico del aforismo bergaminiano, que, según el recientemente fallecido hispanista, constituye una especie de "género fuente» del que se nutrirían los distintos géneros de su producción $(1998,13)$; es más, se produce una «coherencia totalizadora» o «diálogo intragenérico» entre los aforismos y, de manera especial, su escritura ensayística $(1998,15)$. Así, la aforística bergaminiana sirve con frecuencia de laboratorio del pensamiento, de tal forma que muchas de esas iluminaciones lanzadas al aire adquieren un cuerpo y desarrollo en el ensayo. En efecto, ese centro aforístico, alternativamente atractor o irradiante estilístico, subyace en su escritura a modo de «tensión» o «cortocircuito» (Mendiboure 1997, 390) expresivo e intelectual. Como argumenta Jean Michel Mendiboure: «La prosa larga no ha hecho sino integrar la energía estructural del aforismo. El cuerpo necesitaba crecer, pero el nervio central ha seguido siendo el mismo. Y, si es el mismo, es que el objetivo del inquieto Bergamín no cambia: desestabilizar al lector» $(1997,391)$.

Por otra parte, la crítica ha reseñado la maestría conceptista de Bergamín, especialmente con relación a sus aforismos de corte quevedesco-gracianesco, construidos a partir de figuras y estructuras arquitectónicas como equilibrio, armonía u oposición (Dennis 1974, 549). Ahora bien, tal como realizaran Jean Cocteau o Max Jacob -o el propio Ramón Gómez de la Serna- en Le Coq et l'Arlequin (1918) y Art poétique (1922), dos de sus principales influencias contemporáneas, una corriente «de-formadora» atraviesa la meticulosa factura lógica de muchas de sus composiciones que trabajan con dilogías, paronomasias, asociaciones, paralelismos estructurales, modismos, juegos de palabras o «disparates».

Específicamente, González Izquierdo destaca las «contrahechuras» (2002, 326-327) de tópicos y sentencias de la literatura clásica, y del rico acervo compuesto por decenas de refranes y frases hechas repetidas hasta la extenuación y su vaciamiento semántico. Si bien esta suerte de «secularización» paremiológica se aprecia con mayor intensidad en los primeros libros de Bergamín, Gonzalo Penalva considera que esta característica supone uno de los grandes logros de su aforística: la reinvención y actualización de «todo un mundo del idioma olvidado o despreciado por muchos» $(2015,23)$.

12 Al contrario que Antonio Porchia, Bergamín reconoce abiertamente su veta aforística: «Como el fantasma agudo de una flecha lanzaron contra mí tu nombre: aforismo. Y te clavaste en mi corazón» $(1981,88)$. 
No solo de pan vive el hombre; ni de viento el molino (Bergamín 2015, 53). $* * *$

Una creencia que no deja lugar a dudas no es una creencia, es una supersticiosa credulidad. Y un engaño, porque no dudar de nada es dudar de todo (ibíd., 124). $* * *$

Más vale un pájaro volando que ciento en la mano $(1981,103)$.

Sobre este punto habría que recordar la notable influencia de Miguel de Unamuno en el uso de neologismos y hallazgos lingüísticos para resaltar el componente de innovación que el término aglutina. En palabras de González Izquierdo, Bergamín comparte con el escritor vasco el «activismo de la palabra», el interés por «sacar la palabra del anquilosamiento decimonónico, desechando falsos casticismos, y para darle a cada expresión y a cada palabra un significado más allá del sentido común» $(2002,437)$. De hecho, las muestras más tempranas de su escritura aforística fueron publicadas bajo el revelador título de "Aforústica y epigromética», en las que va a predominar, en sintonía con los recogidos en El cohete y la estrella y La cabeza a pájaros, la reflexión metaliteraria junto a homenajes, «glosas» y apuntes sobre autores y obras predilectas.

Sirva de ejemplo los siguientes aforismos que Bergamín dedica al oficio del crítico y al ejercicio de la crítica con vocación taxidermista, seducida por un modo de conocimiento «etnográfico» y positivista:

Hay quienes hacen colección de conocimientos, como si fueran sellos, y llaman cultural al coleccionismo; porque, incapaces de apasionarse, confunden el conocer -que es pasión- con el coleccionar -que es un vicio-.

Se creía que estaba haciendo crítica y estaba haciendo colección.

El regocijo que relampagueaba en los ojos del crítico, detrás de los cristales de sus lentes, no era el de la contemplación estética, sino el del «hallazgo» del coleccionista. $* * *$

El crítico-coleccionista no comprenderá la belleza de ninguna obra, sin haber comprobado antes la etiqueta que lleva; y si no la lleva, la desdeñará sin comprenderla, porque no sirve para su colección (Bergamín 2015, 41-42) ${ }^{13}$.

No obstante, Bergamín, gran admirador y conocedor de los pensées, así como del pensamiento de Nietzsche y de Unamuno, no abandona la vertiente moralista, sino que esta aparecerá reformulada bajo el paradigma filosófico de

${ }^{13}$ Aunque la mayoría de los textos no se publicaron en los libros mencionados, pertenecen al mismo marco cronológico. En su compilación El duende mal pensante, Gonzalo Penalva (2015) recopila la producción aforística comprendida entre 1924 y 1928 de José Bergamín, que se encontraba dispersa en varias revistas de la época como Verdad, Mediodía, Verso y Prosa o Ley. 
la modernidad y de las vanguardias estéticas. Mediante este operar por iluminaciones, el madrileño ahonda en la línea de disolución y crisis del arte y de la razón. En este sentido, en 1930 publica El arte de Birlibiloque, un excelente tratado aforístico que extrapola al terreno de la tauromaquia la dicotomía nietzscheana entre lo apolíneo y lo dionisiaco, encarnados respectivamente por los insignes diestros Joselito y Juan Belmonte. Claro está, reaparece aquí la sombra de los extremos y su posible o inevitable relación dialéctica como reverso iluminador de las antinomias:

Encender una vela a Dios y otra al Diablo es el principio de la sabiduría (Bergamín 1981, 57). $* * *$

Todo lo que tiene un sentido tiene un contrasentido. Todo lo que tiene un Dios tiene un contra-Dios: el Diablo (ibíd., 106). $* * *$

El misterio no está en la sombra: ni en la luz. Está en la duplicidad de la luz y la sombra: en el doble juego, humano y divino, de todo lo crepuscular (ibíd., 114).

Sin embargo, en términos del autor, la dialéctica histórico-materialista provocó «el retroceso zoroástrico del falso dualismo maniqueo» (Bergamín 1983, 51). Bergamín muestra un rechazo frontal a cualquier tipo de reduccionismo simplificador, así como a las operaciones sintéticas que fomentan la conciliación de los contrarios. De esta forma, tal como señala González Izquierdo, los libros del madrileño «quedan ya muy desligados de los sistemas filosóficos basados en la ordenación estricta y lógica de las ideas, en las relaciones inquebrantables y unívocas de causa y efecto, en un sistema racionalista de pensamiento por entonces desacreditado» $(2002,311)$.

Evidentemente, la noción de profundidad no está reñida con otras metodologías más determinadas por el supuesto carácter progresivo de la razón; en cambio, se le presupone a la aforística casi un estatus inferior a la exhaustiva inquisición que realizan otros géneros extensos como el ensayo, la novela o el tratado científico. En la terminología del poeta español, el «pensamiento-larva/ gusano/caracol» se muestra precavido y moroso en sus disquisiciones; por su lado, el «pensamiento-ardilla», inherente a la pirotecnia intelectual que demuestra su escritura, «sabe andarse por las ramas con seguridad sin caerse» (1983, 63). Asimismo, el aforismo bergaminiano no pretende agotar(se) (en) la reflexión, pero el impulso aéreo, connotado por las imágenes de la ardilla, el cohete, la estrella y la cabeza a pájaros, debe ser contenido por una razón habitualmente paradójica: «Una paradoja es como un paracaídas. Sirve para no romperse la cabeza. La paradoja es el paracaídas del pensamiento. Si, al arrojarnos al vacío, no se nos abre oportunamente para sostenernos en el aire, estamos definitivamente perdidos» (Bergamín 1983, 39).

Por otra parte, el «poeta gnómico» (Salinas 1970, 164) José Bergamín encuentra en su particular «arte de temblar» la base para una poética que recoge 
«diversos modos de sentir y de padecer»-«la forma se ve. La palabra se oye. La verdad se entiende. La poesía se sobreentiende»-, pero a los que une la intención de «poner el dedo en la llaga» para «verificar» la gran verdad de toda poesía: el estremecimiento desnudo y auténtico, siempre nuevo y siempre enigmático (Bergamín 1981, 111). Igualmente, la condición jánica de su escritura sapiencial remite a los proverbios y cantares de Antonio Machado, con quien comparte la indiferenciación entre poema y aforismo. En línea con lo dicho acerca del creador sevillano, ni el pensamiento se desliga de su expresión ni la expresión puede ser tal sin el componente reflexivo; es más, como sugiere Mendiboure, «una misma savia corre del uno al otro» $(1995,78)$. Concretamente, el verso se convierte en el vehículo de una producción aforística que bebe de estructuras métricas más o menos consagradas como el haiku, la soleá o la seguidilla:

\author{
¿Por qué - decís- pensamiento poético? \\ -Porque el pensamiento solo es poético (Bergamín 2015, 45). \\ $* * *$ \\ Pensamiento sin expresión, no es pensamiento. Expresión sin pensamiento, no es \\ expresión (ibíd., 45). \\ Todo lo oscuro es mentira. \\ Todo lo claro es verdad. \\ La oscuridad de la noche \\ entraña la claridad (ibíd., 107).
}

En suma, el aforismo constituye una «dimensión figurativa del pensamiento» (Bergamín 1981, 88) que, a la postre, se correspondería metonímicamente con toda actividad mental. Además, frente a los recurrentes rasgos de «verdad», «valor» o «completitud», Bergamín indica que la inconmensurabilidad y la puntería son los dos principales atributos de esta conjunción de aforismo y pensamiento. Como él mismo confiesa, «no importa que el aforismo sea cierto o incierto: lo que importa es que sea certero» $(1981,88)$. La «verdad» resulta conculcada por la propia dinámica del conocimiento, pues se encuentra ineludiblemente comprometida por la mediación del lenguaje. A fin de cuentas, todo contenido sapiencial es susceptible de ser dislocado, recontextualizado o puesto en entredicho con suma facilidad.

No obstante, aunque esta problemática cognoscitiva suele ser abordada a partir del consabido doblete «insuficiencia del lenguaje-inefabilidad de la experiencia o conocimiento», entre las dos posibilidades se tiende a obviar la capacidad poiética del idioma para generar conexiones significativas entre campos lingüísticos y conceptuales extraños a los procesos gramaticales aprendidos. En este sentido, el «arte de temblar» bergaminiano no podría entenderse sin su «arte de disparatar». Al contrario de lo dictado por la lógica, el disparate no supone ninguna expresión de la irracionalidad, sino más bien uno de los caminos abiertos por la razón para superar sus inevitables límites. En palabras 
de Bergamín: «el disparate es pensamiento; es una forma inventiva, creadora, poética del pensamiento» $(2005,27)$.

Como fundamentara Freud en un ensayo ejemplar sobre el chiste y su relación con el inconsciente, el chiste constituye una fuente de placer que, en buena medida, encuentra en el «placer del disparate» una inclinación menguante conforme se va ingresando en el serio y lógico mundo de la madurez mental (1975, 120-121). El género del nonsense, elevado a categoría artístico-literaria gracias a aportaciones tan significadas como las de Edward Lear $-A$ Book of Nonsense (1846)- y Lewis Carroll -Through the Looking-Glass (1871)- en el siglo diecinueve o las de Oliverio Girondo, Ramón Gómez de la Serna o Carlos Edmundo de Ory en el veinte, encuentra en Bergamín un nuevo exponente de esa búsqueda de sentido del sinsentido.

Principalmente, el disparate se cimienta en una maniobra del pensamiento acompañada de una suerte de desactivación y reengarce de las cadenas lógicas del lenguaje $\mathrm{o}$, incluso, de una refundación de las reglas gramaticales ${ }^{14}$. Al respecto, Nigel Dennis puntualiza que «resulta imposible deslindar la subversión lingüística de la subversión ideológica» $(1974,549)$ en el poeta de la Edad de Plata. En efecto, aun cuando los juegos de palabras -ya sea en el plano del significante o del significado- suelen estar en la base de tales operaciones, el disparate ha de presentar un razonamiento de fondo, ya que, para Bergamín, «no es lo mismo el disparate de la razón que la razón del disparate. Aunque sean las dos cosas igualmente disparatadas. No es lo mismo la razón que disparata que el disparate que razona» $(2005,62)^{15}$.

Desde su primer libro de aforismos El cohete y la estrella, la escritura de Bergamín exhibe esta doble vertiente, simbolizada por el cohete -«caña que piensa con brillantez» $(1981,55)$ - y la estrella. La caña sugiere la potencia gregueresca del pensamiento y su libertad asociativa -en parte, identificada con el Witz- a modo de experimento sobre el lenguaje y la realidad; en cambio, la estrella va a preferir «observar» directamente la realidad desde la posición privilegiada del que puede comprobar los efectos sorprendentes que la cohetería bergaminiana produce sobre esta. Inesperada e indirectamente, Machado arroja algo de luz sobre el genio aforístico de José Bergamín:

14 Jorge Sanz señala que la paradoja, mecanismo formal de buena parte de los aforismos bergaminianos, produciría, además de una cierta coherencia macro e interfragmentaria, un efecto similar al del disparate: «fragmentar para unir con nuevos vínculos las cosas» (1998, 34).

$15 \mathrm{Si}$ se sigue el razonamiento expuesto en el excelente ensayo El disparate en la literatura española, Bergamín se apoya en esta distinción para clasificar a autores de los Siglos de Oro según presenten en su obra «razones para disparatar» o «disparates razonados». Mientras que en el primer grupo incluye a Miguel de Cervantes, Santa Teresa de Jesús y Lope de Vega, dentro del segundo menciona a Francisco de Quevedo, Baltasar Gracián y Calderón de la Barca. 


\begin{abstract}
Hay escritores cuyas palabras parecen lanzarse en busca de las ideas; otros, cuyas ideas parecen esperar las palabras que las expresen. El encuentro de unas y otras ideas y palabras, es muchas veces obra del azar. Hay escritores extraños $-\mathrm{y}$ no son los peores- en quienes la reflexión improvisa y la inspiración corrige (Machado 1989b, 1958).
\end{abstract}

De cualquier forma, la fuerza del aforismo no estriba ni en su contenido de Verdad ni en su envoltura léxica, sino en la cantidad de energía liberada como consecuencia de la fusión de los elementos; sin embargo, este teórico requisito no implica que el género no muestre tendencias hacia uno u otro lado. Así, se manifestarán en algunos autores una clara propensión hacia el trabajo verbal y, por el contrario, otros aforistas buscarán en el núcleo semántico su hábitat. En este caso, Bergamín se sabe paradójicamente preso y prófugo de una forma tan proclive -y sometida - a la experimentación lingüística como amiga de la filosofía, pese a que, como él mismo reconoce, «la filosofía es un preludio a la fuga del pensamiento» $(1981,100)$.

A lo largo de este proceso de legitimación de la brevedad, ya de por sí protagonista en el debate genológico, la escritura lapidaria de los dos Antonios -Machado y Porchia- y de José Bergamín ofrecen un excelente muestrario de la renovación e hibridación experimentada por el aforismo clásico. Particularmente, la aforística de Bergamín se va a debatir entre la inteligencia de la pasión pascaliana y la pasión de la inteligencia que definiría la obra de Nietzsche (Bergamín 1981, 108), aunque en vez de decantarse por un modelo u otro, los somete a un proceso de centrifugado lingüístico. En definitiva, si Unamuno personifica para el poeta madrileño la anivolación moderna de la narrativa, el «lirismo esquelético» (Mendiboure 1995, 78) practicado por el creador de la generación del 27 supondría un testimonio ineludible de ese proceso radicalmente contemporáneo de «aforización» de la literatura llevada a su mínima y máxima expresión.

\title{
4. Conclusiones
}

En cierto sentido, el triunvirato de aforistas formado por Antonio Machado, Antonio Porchia y José Bergamín ensayó desde sus respectivas poéticas las posibilidades del género para la transmisión de un tipo de verdad diferente a las proclamadas por la ciencia o la religión. Concretamente, el sevillano explora en sus proverbios y cantares una vía intermedia entre la lírica y la escritura sapiencial que, sin renunciar al estrofismo o al verso, se alimenta de y reformula el abigarrado corpus de sabiduría popular. Además, el binomio Juan de Mairena-Abel Martín, que gozará de continuidad en la obra de otros aforistas contemporáneos como Manuel Neila, propone una alternativa ética y estética -se podría añadir escéptica- a las verdades absolutas e incontrovertibles. Por su parte, Por- 
chia aboga por una concepción epifánica y esencial del pensamiento despojado de su discursividad y adelgazado hasta la mínima expresión. Para el argentino, la razón, amparada por un sistema de normas lingüísticas, ejerce una violencia simplificadora que, además de generalizar una concepción del mundo profundamente dialéctica, omite la capacidad descentradora del lenguaje. Por ello, las voces apuntan a otros modos de aprehensión no coartados por el sujeto racionalista moderno. Finalmente, José Bergamín representa la aforización de la inteligencia o, mejor dicho, la inteligencia hecha arte del aforismo. La poética del madrileño promueve jugar con el verbo para liberarlo de sus cadenas lógico-sintácticas y, de esta manera, resaltar su insuficiencia cognoscitiva. De ahí que Bergamín conciba su aforística como una indagación en las dimensiones figurativas y disparatadas de la palabra y en una forma de pensar analógica.

\section{FUENTES}

Bergamín, José. 1981. El cohete y la estrella. La cabeza a pájaros. Ed. José Esteban. Madrid: Cátedra.

Bergamín, José. 1983. Aforismos de la cabeza parlante. Madrid: Turner.

Bergamín, José. 1994. El arte de birlibirloque. Madrid: Turner.

Bergamín, José. 1998. Las ideas liebres. Aforística y epigramática 1935-1981. Ed. Nigel Dennis. Barcelona: Destino.

Bergamín, José. 2005. El disparate en la literatura española. Ed. Nigel Dennis. Sevilla: Renacimiento.

Bergamín, José. 2015. El duende mal pensante. Aforística musarañera (1924-1983). Ed. Gonzalo Penalva Candela. Granada: Cuadernos del Vigía.

Cerrato, Laura. 1992. «Prólogo». En Voces abandonadas, Antonio Porchia, 9-16. Valencia: Pre-Textos.

Dennis, Nigel. 1998. «José Bergamín, aforista». En Las ideas liebres. Aforística y epigramática 1935-1981, José Bergamín, 9-18. Barcelona: Destino.

Esteban, José. 1981. «Introducción». En El cohete y la estrella. La cabeza a pájaros, José Bergamín, 11-32. Madrid: Cátedra.

Freud, Sigmund. 1975. Obras completas. Vol. VIII. Buenos Aires: Amorrortu Editores.

González Dueñas, Daniel y Alejandro Toledo. 2006. «Epílogo. Un mínimo recorrido por las voces de Antonio Porchia». En Voces reunidas, 231-272. Valencia: Pre-textos.

Machado, Antonio. 1984. Poesías completas. Madrid: Espasa-Calpe.

Machado, Antonio. 1989a. Poesía y Prosa. Prosas completas (1936-1939). Ed. Oreste Macrì. Madrid: Espasa-Calpe.

Machado, Antonio. 1989b. Poesía y Prosa. Poesías completas. Ed. Oreste Macrì. Madrid: Espasa-Calpe.

Machado, Antonio. 1989c. Campos de Castilla. Ed. Geoffrey Ribbans. Madrid: Cátedra. Machado, Antonio. 2010. Sentencias y donaires. Ed. Manuel Neila. Sevilla: Renacimiento. Machado Álvarez, Antonio. 2004. Cantes flamencos y cantares. Barcelona: Biblioteca de Autores Andaluces.

Neila, Manuel. 2010. «Prólogo (el poeta y el filósofo)». En Sentencias y donaires, Antonio Machado, 7-17. Sevilla: Renacimiento. 
Penalva Candela, Gonzalo. 2015. «José Bergamín, en Aforismos». En El duende mal pensante. Aforística musarañera (1924-1983), José Bergamín, 11-27. Granada: Cuadernos del Vigía.

Porchia, Antonio. 1992. Voces abandonadas. Valencia: Pre-Textos.

Porchia, Antonio. 2006. Voces reunidas, ed. Daniel González y Alejandro Toledo. Valencia: Pre-textos.

\section{BIBLIOGRAFÍA CITADA}

Abellán, José Luis. 1979. «La filosofía de Antonio Machado y su teoría de lo apócrifo». El Basilisco 7: 77-83.

Alonso, Dámaso. 1961. Cuatro poetas españoles. Madrid: Gredos.

Andrés, Ramón. 2011. Los extremos. Aforismos. Barcelona: Lumen.

Ángel-Lara, Marco Aurelio. 2011. «Aphoristic Brevity: Towards a Critique of the Common Theoretical Approach». Pensamiento y Cultura 14 (1): 79-93.

Barjau, Eustaquio. 1974. «Antonio Machado: teoría y práctica del apócrifo». Convivium. Revista de Filosofía 43: 89-120.

Benarós, León. 1988. Antonio Porchia: con estudio preliminar, testimonios, juicios críticos, cartas inéditas y antología de voces. Buenos Aires: Hachette.

Camacho, Carmen. 2016. Zona franca. Granada: Cuadernos del Vigía.

Cejudo Velázquez, Pablo. 1986. "Machado de cuerpo entero en "los apócrifos"». Letras 11-12: 103-120.

Cruz Pérez, Francisco José. 1991. «Antonio Porchia: la experiencia del abismo». Cuadernos Hispanoamericanos 498: 65-74.

Cruz Pérez, Francisco José. 1994. «Antonio Porchia: el puente de la disponibilidad». Cuadernos Hispanoamericanos 525: 145-150.

Dennis, Nigel. 1974. «José Bergamín y la exaltación del disparate». Cuadernos Hispanoamericanos 288: 539-556.

Dennis, Nigel. 1986. José Bergamín. A Critical Introduction 1920-1936. Toronto: University of Toronto Press.

Gasparini, Pablo. 2009. «Un inmigrante entre extranjeros: Antonio Porchia como "gnomon" del misterio». Confluenze: Rivista di Studi Iberoamericani 1 (2): 71-80.

González, José Ramón, ed. 2013. Pensar por lo breve. Aforística española de entresiglos (1980-2012). Gijón: Trea.

González Izquierdo, María. 2002. Tradición y renovación poética en la obra de José Bergamin. Tesis doctoral. Universidad de La Laguna. Accesible en: <ftp://tesis.bbtk.ull.es/ ccssyhum/cs117.pdf>.

Gullón, Rircardo. 2006. Unidad en la obra de Antonio Machado. Alicante: Biblioteca Virtual Miguel de Cervantes. Accesible en: <http://www.cervantesvirtual.com/obra-visor/ unidad-en-la-obra-de-antonio-machado-0/html/00bb4958-82b2-11df-acc7002185ce6064_2.html\#I_0_>.

Gutiérrez-Girardot, Rafael. 1969. Poesía y prosa de Antonio Machado. Madrid: Guadarrama.

Helmich, Werner. 1998. «Cohérence et fragmentation de la pensée aphoristique d'Antonio Porchia». En Fragment(s), fragmentation, aphorisme poétique, coord. Marie Jeanne Ortemann, 77-99. Nantes: Universidad de Nantes - CRINI.

Helmich, Werner. 2006. «L'aforisma como genere letterario». En La Brevità felice. Contributi alla teoría e alla storia dell'aforisma, ed. Mario Andrea Rigoni, 19-49. Venezia: Marsilio. 
Mendiboure, Jean-Michel. 1995. «Verso y aforismo: una lectura de Duendecitos y coplas». En En torno a la poesía de José Bergamín, ed. Nigel Dennis, 71-83. Lleida: Pagès Editors - Universitat.

Mendiboure, Jean-Michel. 1997. «El nervio aforístico de la escritura de José Bergamín». Paremia 6: 389-392.

Morábito, Fabio. 2008. «Antonio Porchia: la brevedad del extranjero». Acta Poética 29 (2): 141-159.

Novalis (Friedrich Leopold von Hardenberg). 2006. Gérmenes o Fragmentos. Sevilla: Renacimiento.

Rodríguez, Guillermo. 1975. «Antonio Porchia: una logia secreta». Cuadernos Hispanoamericanos 297: 650-657.

Salinas, Pedro. 1970. Literatura española del siglo XX. Madrid: Alianza.

Sampedro, Henry Fernando. 2009. «El susurro de las Voces de Antonio Porchia, señalando otras latitudes». Cuadernos de Literatura XIV, 26: 216-227.

Sanz Barajas, Jorge. 1998. José Bergamín. La paradoja en revolución (1921-1943). Madrid: Ediciones Libertarias.

Saubidet, Magdalena. 1979. «Las Voces de Antonio Porchia». La Prensa, 17 de junio.

Sobejano, Gonzalo. 1976. «La verdad en la poesía de Antonio Machado: de la rima al proverbio». Journal of Spanish Studies: Twentieth Century 4: 47-73. Accesible en: http://www.jstor.org/stable/27740710.

Fecha de recepción: 22 de enero de 2018.

Fecha de aceptación: 03 de abril de 2018. 